\title{
A SUBJETIVIDADE NA FORMAÇÃO DO LEITOR LITERÁRIO NO ESPAÇO DO PROGRAMA BALE
}

\section{THE SUBJECTIVITY IN THE FORMATION OF THE LITERARY READER IN THE SPACE OF THE PROGRAM BALE}

\author{
Keutre Gláudia da Conceição Soares Bezerra* \\ Maria Lúcia Pessoa Sampaio**
}

\begin{abstract}
Resumo: Este trabalho tem como foco o estudo do Programa BALE (Biblioteca Ambulante e Literatura nas Escolas) como espaço mobilizador da subjetividade na formação do leitor. O objetivo é identificar os sentidos subjetivos que são mobilizados na atuação dos participantes no que concerne à sua constituição leitora, tendo como base teórica o estudo da subjetividade na perspectiva histórico-cultural. No tocante a metodologia, trata-se de uma pesquisa de cunho qualitativo, com suporte nos postulados da Epistemologia Qualitativa, que considera a pesquisa como um espaço dialógico e o conhecimento como um processo construtivo-interpretativo. Com base no pressuposto metodológico apresentado, a construção da informação se deu a partir do uso do questionário aberto. Os resultados preliminares indicam que ao atuarem no Programa BALE, os sujeitos desenvolvem sentidos subjetivos que transformam suas atitudes com relação à leitura e consequentemente despertam e/ou ampliam a atuação como leitores.

Palavras-chave: Formação do leitor, programa BALE, subjetividade, mediação de leitura.
\end{abstract}

Abstract: This paper focuses on the study of the BALE Program (Travelling Library and Literature at Schools) as a space mobilizing subjectivity in the formation of the reader. The aim is to identify the subjective meaning which are infered in the participants' actions regarding the reading constitution, having as theoretical base the study of subjectivity in the historical-cultural perspective. Regarding methodology, this is a qualitative research, supported by the postulates of Qualitative Epistemology, which considers research as a dialogical space and knowledge as a constructive-interpretative process. Based on the methodological assumption presented, the construction of the information was based on the open questionnaire. The preliminary results have pointed out that when acting within the BALE Program, subjects construct subjective meaning that transform their attitudes towards reading and consequently awaken and / or broaden their performance as readers.

Keywords: Reader's formation, BALE program, subjectivity. Reading mediation.

\section{Primeiras considerações}

O presente artigo provém dos estudos realizados na elaboração da Tese de Doutorado intitulada Expressão criativa e subjetividade na contação de histórias no programa BALE (Biblioteca Ambulante e Literatura nas Escolas), que está sendo elaborada no Programa de Pós-Graduação em Letras - PPGL, da Universidade do Estado do rio Grande do Norte - UERN.

Objetivamos apresentar um estudo acerca do Programa BALE - Biblioteca Ambulante e Literatura nas Escolas como espaço mobilizador da subjetividade na formação dos integrantes do programa no tocante à leitura. Procuramos na investigação, identificar os sentidos subjetivos que são mobilizados na atuação dos participantes no

\footnotetext{
* Mestra em Letras, Doutoranda em Letras pelo Programa de Pós-Graduação em Letras - PPGL, da Universidade do Estado do Rio Grande do Norte - UERN. E-mail: keutresoares@gmail.com.

** PhD no Laboratoire d'Etudes Romanes, na Équipede Linguistique des Langues Romanes na Université Paris 8, France. Docente do Curso de Doutorado em Letras no Programa de Pós-Graduação em Letras PPGL, da Universidade do Estado do Rio Grande do Norte - UERN. E-mail: malupsampaio@ hotmail.com.
} 
que se refere à constituição leitora a partir do trabalho de mediação que os mesmos realizam com o texto literário, tendo como base teórica o estudo da subjetividade na perspectiva histórico-cultural.

No tocante à metodologia, trata-se de uma pesquisa de cunho qualitativo, com suporte nos postulados da Epistemologia Qualitativa, proposta apresentada como embasamento teórico-metodológico e epistemológico dos estudos da Teoria da Subjetividade numa perspectiva histórico cultural de González Rey $(2003,2005,2015)$. Esse aporte epistemológico e metodológico define o empírico como o momento de confrontação entre a teoria e a realidade, no qual o pesquisador torna-se sujeito ativo na construção do conhecimento. Além disso, considera a pesquisa um espaço dialógico e o conhecimento um processo construtivo-interpretativo.

Com base no pressuposto teórico-metodológico apresentado, a construção da informação se deu a partir da elaboração de um questionário aberto (GONZÉLEZ REY, 2003), que foi respondido por 25 integrantes do Programa. A análise da informação construída está pautada no princípio construtivo-interpretativo como característica principal do processo da pesquisa, que de acordo com González Rey e Mitjáns Martínez (2017), deve ser dialógico, entendendo o conhecimento como uma construção.

\section{O BALE como espaço de formação do leitor}

O programa BALE vem promovendo a formação do leitor desde o ano de 2007. Segundo as idealizadoras, Maria Lúcia Pessoa Sampaio e Renata de Oliveira Mascarenhas, o seu objetivo principal é disseminar o gosto pela leitura a partir do texto literário, bem como outros gêneros que venham favorecer a formação de leitores e mediadores de leitura, tanto em espaços escolares, como não escolares (SAMPAIO e MASCARENHAS, 2007).

Trilhando um caminho de sucesso, o BALE iniciou como um projeto de extensão, permanecendo nessa categoria no período de 2007 a 2011, vinculado ao Departamento de Educação, em parceria com o departamento de Letras Vernáculas, no Campus Avançado Professora Maria Elisa de Albuquerque Maia-CAMEAM, da Universidade do Estado do Rio Grande do Norte-UERN. No ano de 2012, o projeto alcançou o status de Programa de Extensão, subdividindo-se em cinco ações: BALE Formação, voltado para a formação de novos mediadores de leitura, tanto na Universidade quanto na Educação Básica; BALE Ponto de Leitura, que se dedica à mediação do contato do leitor com o livro; BALE em Cena, que atua principalmente com a encenação das histórias; Cine BALE Musical, que desenvolve atividades através da inserção da música e do cinema; e, por fim, BALE Net, responsável por gerenciar o programa no mundo virtual. Cada ação visa dedicar-se a uma forma específica de veiculação da arte literária, entretanto, todas trabalham em conjunto, com o objetivo maior de mediar o caminho entre o leitor e o livro.

A transição de projeto de extensão, que visa uma única ação, para programa de extensão, que desenvolve várias ações, foi um grande passo na trajetória do BALE, pois foi possível atender a uma demanda maior do público, inserindo com isso diversas linguagens no trabalho com a mediação de leitura (SAMPAIO, 2012). Ainda de acordo com uma das idealizadoras, "A ideia de torná-lo programa advém da grande proporção que o projeto alcançou. Ganhando espaço, reconhecimento e aceitação da comunidade acadêmica, bem como do público atendido, [...]”. (SAMPAIO, 2012, p. 12). Assim, 
enquanto extensão o BALE pode atender a uma demanda maior de formação de leitores, pois como tal, consegue articular as ações propostas de forma multidisciplinar, além de desenvolver atividades de pesquisa e ensino.

Além de Programa de Extensão, o BALE se tornou um ambiente de pesquisa, construindo um banco de dados significativo, com documentos escritos, fotos e registros em vídeos de suas ações. Constituindo-se, portanto em um espaço valioso para a produção acadêmica, possibilitando a investigação em diversos enfoques, especialmente no que se refere à formação do leitor. Nesse sentido, há uma vasta produção teórica a respeito do BALE, como artigos em periódicos, livros e capítulos de livros, monografias de conclusão de curso, tanto na graduação quanto na pós-graduação lato sensu, bem como dissertações de mestrados e a tese de doutorado que originou o presente trabalho.

Nessa perspectiva, a leitura no BALE é vista sob o prisma apontado por Larrossa (2002), ao defini-la como "[...] algo que nos forma, (ou nos trans-forma e nos de-forma), como algo que nos constitui ou nos põe em questão naquilo que somos" (LARROSSA, 2002, p. 133, grifo do autor). O sujeito leitor é assim concebido como alguém que encontra na leitura não só uma habilidade que o coloca em atividade na sociedade letrada em que vivemos, mas o torna um ser que analisa seu dia a dia de forma interpretativa, buscando compreender a si mesmo e ao mundo que o rodeia.

A prática da leitura é então encarada no BALE como uma forma profícua de fazer social, um direito de todos. Nesse sentido, o programa fortalece/endossa/auxilia esse objetivo, oportunizando o contato com o livro, contribuindo assim para a formação cultural. Mediante esse contexto, a intenção da equipe do Programa é mediar a relação do leitor com o livro, fazendo com que esse contato se realize de maneira satisfatória.

Para alcançar o objetivo desejado, o caminho escolhido pelo BALE tem como suporte o texto literário em suas mais variadas formas, pressupondo, como enfoca Calvino, que a literatura, "[...] nos permite entender quem somos e aonde chegamos" (CALVINO, 2004, p. 16). Além disso, a literatura nos torna mais humanos, aspecto defendido por Cândido (2004) ao abordar a humanização como:

[...] o processo que confirma no homem aqueles traços que reputamos essenciais, como o exercício da reflexão, a aquisição do saber, a boa disposição para com o próximo, o afinamento das emoções, a capacidade de penetrar nos problemas da vida, o senso da beleza, a percepção da complexidade do mundo e dos seres, o cultivo do humor. A literatura desenvolve em nós a quota de humanidade na medida em que nos torna mais compreensivos e abertos para a natureza, a sociedade, o semelhante (CÂNDIDO, 2004, p. 180).

Podemos alegar que os objetivos almejados no Programa, no que concerne à formação do leitor, baseia-se numa concepção de literatura tal como aborda Cândido (2004), ou seja, concebe o texto literário como uma forma de arte que desperta no sujeito sua humanidade. A mobilização dos sentimentos e das emoções que a literatura provoca é o ponto de partida do trabalho do BALE na pretensão de alcançar o intuito de formar leitores.

$\mathrm{O}$ aspecto mais relevante para a concretização o propósito do trabalho realizado pela equipe do BALE, diz respeito à mediação de leitura. Entendemos mediação de leitura como uma forma de fazer o texto literário chegar até as pessoas a partir de diversas estratégias, visando uma aproximação do público com o texto literário. Para tanto, utilizamos diversas formas de apresentar a literatura, bem como diversos tipos de obras, desde os contos populares até a literatura canônica. 
A concepção de mediação aqui apresentada parte dos estudos de Vygotsky (2005, 2007), que aborda a interação como a principal forma do sujeito constituir-se em ser cultural, histórico e social a partir da troca de experiências com os demais sujeitos. Para o autor "a transmissão racional e intencional de experiência e pensamento a outros requer um sistema mediador, cujo protótipo é a fala humana, [...]" (VYGOTSKY, 2005, p. 07). A ideia de mediação trazida pelos estudos de Vygotsky se tornou de suma importância nas discussões e nas práticas que abordam essa temática.

Entre os estudiosos do assunto, destacamos ainda o enfoque de Oliveria ao afirmar que "Mediação em termos genéricos é o processo de intervenção de um elemento intermediário numa relação; a relação deixa, então, de ser direta e passa a ser mediada por esse elemento" (OLIVEIRA, 2002, p. 26). No contexto do BALE, esse elemento se configura na pessoa do mediador de leitura, que utiliza formas diversificadas para fazer a ponte entre o livro e o leitor. Dentre as estratégias utilizadas, destacamos a contação de histórias, que é a principal forma de atuação do programa junto ao público, tornando-se a marca do mesmo como ação extensionista.

A estratégia mencionada visa à promoção do encontro do público com o livro de literatura por meio da atividade de contação de histórias, considerada como uma prática que faz parte da vida do homem desde tempos ancestrais, tendo se perpetuado devido ao fato de as histórias narradas ser uma forma de emocionar e encantar as pessoas através do mágico revelado nos enredos, que é tão caro à formação humana. Isso porque a narrativa mágica é uma via por onde transita os sentimentos universais que movimentam a humanidade de cada um. (CAVALCANTI, 2002)

Nessa perspectiva, contar histórias se torna uma maneira de levar a emoção da literatura para o público, que ao encantar-se pelo que o literário revela, poderá ir buscar esse encantamento na forma de livro, tornando-se então um leitor. Sobre esse aspecto, Sisto defende a relevância de contar histórias como forma de emocionar; para o autor, "o que vale mais é sentir a liberdade de ser coautor da história narrada e poder receber a experiência viva e criada na imaginação, o cenário, as roupas, as caras dos personagens [...]" (SISTO, 2005, p. 20). Na citação, percebemos a defesa do autor pelo ato de contar histórias como forma de suscitar os sentimentos do ouvinte, o que consideramos um caminho promissor na formação do leitor.

Nesse sentido, enfatizamos a relevância do BALE como programa de formação de leitores, dado que suas ações visam especialmente o acesso e a disseminação do texto literário, pois segundo Muniz e Oliveira, "A aproximação ou o afastamento do leitor do texto literário dependerá, em muitos casos, das interações pessoais e verbais experienciadas na trajetória de vida em diversos ambientes, [...]" (MUNIZ e OLIVEIRA, 2014, p. 45). A fala das autoras nos leva a pensar o cenário do BALE como um ambiente organizado para possibilitar essa formação leitora, encarada como uma prática social, como abordada por Cosson, quando afirma que: "Aprender a ler é bem mais do que adquirir uma habilidade, e ser leitor vai além de possuir um hábito ou uma atividade regular. Aprender a ler e ser leitor são práticas sociais que mediam e transformam as relações humanas. [...]" (COSSON, 2011, p. 40)

A abordagem do autor vai ao encontro da concepção de leitura adotada pelo BALE, ou seja, conceber a leitura como uma prática social implica considerá-la como uma valiosa maneira de provocar interações entre leitor e texto através da mobilização de sentimentos, como imaginação, emoção e sensibilidade. Estes sentimentos estão presentes na mediação de leitura feita pela contação de histórias, pois ao ouvir as 
narrativas, as pessoas são levadas a um estado de fantasia que é natural no ser humano, podendo assim aproximar-se da obra literária e converter-se em leitores concretos.

\section{Uma breve discussão sobre subjetividade}

A experiência humana vem suscitando estudos de várias áreas das ciências, especialmente as antropossociais, que buscam uma compreensão de como o sujeito se articula com seu meio social e cultural na produção de conhecimentos, na elaboração de conceitos e na própria formação psicológica, (GONZÁLEZ REY, 2005). Em nosso trabalho, necessitamos esboçar um pouco do contexto de investigações que permitiram a consolidação dos pressupostos teóricos que embasam a presente pesquisa, entre eles a teoria da subjetividade elaborada pelo pesquisador González Rey $(2003,2005,2012)$.

As conjecturas teóricas apresentadas pelo referido pesquisador, foram formuladas a partir de estudos psicológicos que são direcionados para algumas áreas das ciências antropossociais, em especial a educação, que vem desenvolvendo pesquisas de extrema relevância para a compreensão da formação do ser humano em variados aspectos a partir de proposições oriundas de outras ciências, como a Psicologia.

Mediante o exposto, fica evidente a necessidade de apontamentos em torno da organização dos estudos da subjetividade numa perspectiva histórico-cultural abordada por González Rey (2003), na tentativa de discutirmos um pouco a respeito do percurso científico do qual emerge os conhecimentos elaborados pelo autor e que dão suporte a esta e a muitas pesquisas na atualidade.

Para o autor, no desenvolvimento de sua teoria, a princípio o termo subjetividade significaria "[...] a organização complexa do sistema de sentidos e significados que caracteriza a psique humana individual e os cenários sociais nos quais o sujeito atua. [...]" (GONZÁLEZ REY, 2003, p. XI). No entanto, para um melhor entendimento dessa perspectiva teórica é preciso vislumbrar algumas das bases científicas que precedem sua formulação.

Em sua obra Sujeito e Subjetividade: uma aproximação histórico-cultural, o autor citado traz uma abordagem do desenvolvimento da Psicologia enquanto ciência, traçando um percurso histórico que visa à compreensão da evolução do pensamento psicológico ao longo da história e da construção da pesquisa científica na área psicológica. O autor coloca a visão histórica de Wundt como um importante antecedente na definição do "[...] caráter histórico dos processos psicológicos complexos do homem. [...]" (GONZÁLEZ REY, 2003, p. 03). Assim, estudar os processos psicológicos humanos aparece como um passo significativo na constituição da Psicologia enquanto ciência.

Ainda de acordo com González Rey (2003), os pressupostos da teoria de Elliott também contribuíram para a constituição da Psicologia numa perspectiva históricocultural, da qual deriva a teoria da subjetividade aqui abordada. Segundo González Rey, o estudo de Elliot, "[...] estabelece o compromisso permanente dos processos de subjetivação com o contexto histórico-cultural do sujeito e dá protagonismo ao sujeito em seu caráter ativo e criativo no processo de subjetivação das influências sociais. [...]" (GONZÁLEZ REY, 2003, p. 57). Dessa perspectiva, a subjetividade se forma dentro do campo de ação do sujeito e dos cenários sociais nos quais se desenvolve. 
Com base nestes e em outros pressupostos, González Rey (2003) apresenta a subjetividade considerando-a como dialética, dialógica, e sistêmica, características que atribui também a psique. Sendo assim, para o autor, a subjetividade,

É um sistema simbólico-emocional orientado à criação de uma realidade peculiarmente humana, a cultura, da qual a própria subjetividade é condição de seu desenvolvimento e dentro da qual tem a sua própria gênese, socialmente institucionalizada e historicamente situada. (GONZÁLEZ REY e MITJÁNS MARTÍNEZ, 2017, p. 27).

O conceito apresentado aqui nos leva a compreender a subjetividade como um aspecto do ser humano que se constrói a partir da relação com os outros indivíduos nos espaços sociais nos quais interage e com os quais desenvolve um sistema cultural. Em outra obra González Rey (2005) reforça que "A subjetividade é uma construção histórico-cultural. Todo processo é vivenciado primeiro como externo em relação a outros, para depois se internalizar [...] a partir da construção própria, de sentido, e de cada indivíduo social. [...]" (GONZÁLEZ REY, 2005a, p. 87, grifo do autor).

Nesse sentido, González Rey (2003, 2005a, 2005b, 2007, 2012, 2015) constrói uma teoria que visa o estudo da subjetividade humana a partir de um marco históricocultural. A mesma tem como propósito possibilitar o desenvolvimento de uma prática de pesquisa na área da Psicologia que se diferencie da proposta de estudo positivista. No entanto, em decorrência dos resultados alcançados e da divulgação dos estudos do autor, as pesquisas que se dedicam ao estudo da subjetividade tendo como base os pressupostos teóricos e metodológicos apontados por González Rey e seu grupo de estudos se tornaram referência também em outras áreas, dentre elas a Educação.

De acordo com o estudioso mencionado, a Psicologia soviética foi o contexto onde surgiram as discussões que possibilitaram o nascimento da psicologia históricocultural. É essa corrente de pensamento que embasa o que Mitjáns Martínez (2005) denomina de Teoria Psicológica da Subjetividade para se referir as elaborações conceituais desenvolvidas por González Rey. De acordo com a autora, “[...] partindo de diversas influências filosóficas e teóricas e do trabalho científico criativo do autor, essa teoria tenta dar visibilidade às formas complexas por meio das quais se expressa o psiquismo humano a partir de uma perspectiva histórico-cultural". (MITJÁNS MARTÍNEZ, 2005, p. 14)

Nessa perspectiva, os estudos que se debruçam sobre aspectos referentes à subjetividade humana tendo por base a representação da mesma sob o prisma da teoria histórico-cultural, precisam levar em conta os pressupostos investigativos epistemológicos que influenciaram a constituição da subjetividade enquanto categoria de estudo que perpassa as mais diversas ciências.

A concepção histórico-cultural no bojo de sua construção, teve como inspiração a proposição marxista do materialismo dialético como alternativa criativa e revolucionária no contexto das investigações científicas do início do século XX, especialmente na psicologia soviética. Sob a influência principalmente dos trabalhos de Vygotsky e Rubinstein que procuraram compreender o psiquismo humano de um ponto de vista sócio-histórico, a psicologia histórico-cultural conduziu para o centro dos estudos psicológicos aspectos como o cognitivo e o afetivo, o social e o individual, superando assim a dicotomia existente entre essas e outras categorias. (GONZÁLEZ REY, 2003). 
Nesse sentido, a proposta de González Rey (2005b) para o estudo da subjetividade a partir da concepção histórico-cultural enfatiza a representação dos sistemas complexos da sociedade. Com isso, a concepção da psique como algo interno ao indivíduo deu lugar à consideração da psique como um sistema complexo, oriundo da produção histórico-cultural do sujeito. Assim, na constituição da subjetividade ganha destaque a ação do sujeito, na qual estão envolvidas as "configurações de sentido que integram o atual e o histórico em cada momento de ação do sujeito nas diferentes áreas de sua vida." (GONZÁLEZ REY, 2005b, p. 35).

Assim, no entendimento da subjetividade está implicado diretamente as relações que o sujeito estabelece com o meio e com os demais indivíduos no curso de suas ações que permitem a produção da história e da cultura. De acordo com González Rey,

\begin{abstract}
La subjetividad humana como forma de lo real, existe en las estructuras simbólicas y de sentido subjetivo distintivas del hombre, las cuales no aparecen de una vez y por todas, como atributos universales del desarrollo, sino que se reconstituyen de forma diferente en el curso de este proceso a través de las formas de relación social en que el sujeto va desplegando su existencia social. El mundo donde el hombre vive se constituye subjetivamente en su personalidad, así como en las diferentes formas sociales en Ias que despliega su acción. (GONZÁLEZ REY, 2008, p. 07).
\end{abstract}

Para o autor, os processos simbólicos e de sentido que atuam na constituição da subjetividade e que são exclusivos do ser humano são construídos no decorrer das relações sociais do sujeito a partir do caráter simbólico que envolve os processos sociais. Estes, são responsáveis pelas modificações que se instalam no interior da realidade humana e que atuam na formação da personalidade e movimentam recursos subjetivos provenientes da ação do homem.

Mediante o exposto, compreendemos que na subjetividade da perspectiva abordada, o indivíduo é reconhecido como agente ativo no processo de socialização e produção cultural, o que possibilita o tratamento do indivíduo e da sociedade numa relação indivisível. Nessa relação à experiência humana é encarada como a matéria prima da vida social e da construção da personalidade individual do sujeito, influenciada pelas atividades e relações que este institui no curso de sua existência. (GONZÁLEZ REY, 2001, 2005b)

Em consonância com a abordagem histórico-cultural da subjetividade, Montenegro (2012) enfoca que o homem nessa concepção é caracterizado pela capacidade de interpretar, agir e modificar a realidade, em um processo dialético no qual se edifica enquanto ser social e histórico. Isto significa que o sujeito ao agir sobre a realidade, movimenta a subjetividade a partir das significações que esta realidade traz para sua personalidade, não de modo objetivo ou linear, mas a partir dos sentidos que são elaborados no contexto das ações do sujeito.

Seguindo esse ponto de vista, González Rey determina que "a subjetividade alimenta-se de uma produção simbólica de origem cultural, mas também de uma

\footnotetext{
$\dagger$ “A subjetividade humana como forma do real existe nas estruturas simbólicas e de significado subjetivas do homem, que não aparecem de uma vez por todas, como atributos universais do desenvolvimento, mas se reconstituem de forma diferente no decorrer deste processo através das formas de relação social. o mundo onde o homem vive se constitui subjetivamente em sua personalidade, assim como as diferentes formas sociais nas quais implanta sua ação."
} 
produção social que, além de simbólica é portadora de um caráter subjetivo. [...]." (2012). Desse modo, embora a vida social e cultural seja a matéria prima de produção do sujeito, não há uma relação direta entre a experiência e a forma de subjetivação da mesma no indivíduo, visto que, os sentidos subjetivos não se processam como reações pontuais a influências externas.

Podemos então compreender que a subjetividade não é um sistema linear, muito menos contínuo, é antes, um sistema pluridimensional, que integra os aspectos interno e externo numa mútua e permanente influência, permitindo assim o surgimento constante de novos processos. Sendo assim, tanto as relações sociais atuais, quanto as vivenciadas ao longo da história de vida interagem na expressão do sujeito e de sua configuração subjetiva. (SCOZ, TACCA E CASTANHO, 2012 subj, em foco)

A partir do exposto, consideramos que a pesquisa científica que envolve a subjetividade humana na perspectiva histórico-cultural como categoria, necessita compreendê-la como um sistema aberto e em desenvolvimento contínuo, além de ser complexo e plurideterminado. Esse sistema é afetado pelo desenvolvimento da sociedade, dos sujeitos e dos processos sociais, numa dinâmica complexa de relações que se concretizam nas ações individuais desencadeadas nos espaços de atuação dos indivíduos.

Nesse sentido, a subjetividade se define como os processos que são gerados pelos seres humanos ao viverem uma experiência a partir do caráter gerador de sentidos que a interação proporciona. Como aborda González Rey, "el desarrollo subjetivo no tiene etapas, no tiene momentos, el ocurre de forma singular y diferenciada en cada ser humano. [...]"* (GONZÁLEZ REY, 2001, p. 09). Com isso, entendemos que as configurações subjetivas que levam ao desenvolvimento subjetivo surgem em momentos diferentes e a partir de trajetórias distintas na vida de cada pessoa em particular.

Em outra obra recente, González Rey e Mitjáns Martínez (2017) confirmam o exposto reafirmando a subjetividade como um sistema configuracional, organizado com base em configurações subjetivas diversas que emergem em diferentes momentos e contextos da experiência humana. Assim, o estudo da subjetividade exige a interdisciplinaridade, já que as características subjetivas representam uma ação constitutiva de cada momento da ação do sujeito nos mais diversos aspectos de sua convivência em sociedade.

Partindo dos pressupostos apresentados acima, compreendemos o espaço social do programa BALE como um espaço no qual os sujeitos que fazem a mediação de leitura vivenciam experiências sociais significativas para a construção de sua subjetividade enquanto mediadores de leitura, pois ao interagirem com os outros na mediação de leitura, estão vivendo processos sociais que desencadeiam a consolidação de novos significados em suas relações sociais.

\section{O BALE e a subjetividade na formação do leitor}

Para desencadearmos uma reflexão em torno da subjetividade e de como é mobilizada no contexto do programa BALE no tocante à formação do leitor, precisamos

\footnotetext{
\$ “O desenvolvimento subjetivo não tem estágios, não tem momentos, ele ocorre de forma singular e diferenciada em cada ser humano."
} 
levar em conta algumas considerações advindas dos apontamentos teóricos de González Rey, (2003) e de alguns de seus colaboradores sobre subjetividade. Para isso, buscamos compreender os sentidos subjetivos que são mobilizados pelos participantes no tocante à trajetória enquanto leitores.

É importante mencionar que a formação do leitor se configura como o ponto de partida do trabalho no Programa BALE na qualidade de ação extensionista, que vem desenvolvendo um significativo trabalho no tocante a formação de leitores e ao fomento à leitura na cidade de Pau dos Ferros e região, no Estado do Rio Grande do Norte. Além disso, a atuação do programa tem se expandido muito, chegando a desenvolver trabalhos em outros estados do Brasil, bem como em outros países, como em Cabo Verde na África, onde foram desenvolvidas oficinas sobre o BALE.

Vale ressaltar que uma das principais estratégias desenvolvidas pelo BALE na mediação da leitura é a contação de histórias. O contador de história do BALE, mesmo sem a pretensão de desenvolver essa atividade com status de profissão, se assemelha ao contador profissional moderno. Este, segundo Andrade, está "[...] saindo do espaço familiar e percorrendo novos espaços, como escolas, feiras do livro, livrarias, bibliotecas, teatros, shoppings, saindo do anonimato e passando a desenvolver uma atividade autoral, de certa forma profissional." (ANDRADE, 2012, p. 26). O contador moderno usa como ferramenta principal de sua atuação a criatividade, aspecto que vem sendo estudado com frequência por diversos profissionais, dos quais destacamos Albertina Mitjáns Martínez (1997, 2012).

Em seus estudos, Mitjáns Martínez (1997) alerta que não pretende formular um conceito fechado de criatividade, dada a complexidade que envolve a temática e os inúmeros estudos que tem se preocupado em determinar uma conceituação para o processo criativo. Do ponto de vista da autora, “[...] criatividade é o processo de descoberta ou produção de algo novo que cumpre exigências de uma determinada situação social, processo que, além disso, tem um caráter personológico." (MITJÁNS MARTÍNEZ, 1997, p. 54)

Por esse ângulo, a criatividade aparece como um processo, e como tal, está implicado na constituição do sujeito, levando em conta os aspectos sociais e culturais inerentes a toda formação humana, sendo desse modo um movimento no qual a subjetividade opera de maneira significativa na constituição do sujeito no espaço social. Esse sujeito, que também é cultural, vai se formando na medida em que atua e participa da interação social com o outro e com a sociedade da qual compartilha.

Tomando como objeto de análise os mediadores de leitura do BALE, veremos que o espaço social no qual o programa atua, surge como um elemento fundamental na construção subjetiva desse sujeito enquanto criativo. Para pensarmos a categoria de sujeito e sua relação com o social apontamos o pensamento de Gonzalez Rey (2003), que discute a compreensão do sujeito na perspectiva da teoria histórico-cultural da subjetividade. $\mathrm{O}$ autor aponta em um de seus estudos que:

O sujeito em sua processualidade reflexiva intervém como momento constituinte de si mesmo e dos espaços sociais em que atua, a partir dos quais pode afetar outros espaços sociais. O sujeito representa um momento de subjetivação dentro dos espaços sociais em que atua e, simultaneamente, é constituído dentro desses espaços na própria processualidade que caracteriza sua ação dentro deles, a qual está sempre comprometida direta ou indiretamente com inúmeros sistemas de relação. (GONZALEZ REY, 2003, p. 235). 
Com fundamento na citação anterior, observamos que o sujeito desponta como "constituinte de si mesmo", ou seja, o autor traz à tona a importância dos fatores internos para os processos subjetivos que afloram na construção social do sujeito, que não se configura como um processo individual, mas construído na experiência com o outro em cada contexto de atuação, levando em conta também os elementos externos. Para o autor "[...] o sujeito está sempre em atividade em seus diferentes espaços de relação social" (GONZALEZ REY, 2007, p. 144). É nessa atuação nos espaços sociais que o sujeito elabora os processos subjetivos, vinculados às atividades que trazem significado para a formação do indivíduo, construindo assim novos sentidos subjetivos que atuam diretamente na constituição da pessoa.

Em outra obra, o autor mencionado aborda a subjetividade como "[...] um sistema complexo capaz de expressar através dos sentidos subjetivos a diversidade de aspectos objetivos da vida social que concorre em sua formação. [...]" (GONZÁLEZ REY, 2015, p. 19). Com isso, podemos perceber o quanto a discussão em torno da subjetividade se configura como algo complexo, que envolve diversos aspectos da formação humana, requerendo assim um olhar investigativo aguçado e embasado em uma construção do conhecimento que leve em conta o sujeito como um ser social, cultural e histórico, em constante estado de construção.

As ponderações apresentadas nos levam a refletir sobre as palavras de Gonzalez Rey, quando afirma que, "a subjetividade somente pode ser estudada a partir de uma perspectiva construtiva interpretativa. [...]" (GONZÁLEZ REY, 2007, p. 134). Isso devido ao fato de a subjetividade não permitir a exploração de dados de maneira objetiva, sem considerar a complexidade que a envolve. Essa natureza complexa demanda do pesquisador uma postura criativa, além do envolvimento investigativo direto com o objeto de estudo.

Um aspecto que não podemos deixar de mencionar diz respeito à concepção de sentido subjetivo na ótica do autor acima citado. Para ele o sentido subjetivo corresponde "[...] a unidade dos aspectos simbólicos e emocionais que caracterizam as diversas delimitações culturais das diferentes práticas humanas em um nível subjetivo" (GONZÁLEZ REY, 2005a, p. 44). O estudioso acrescenta ainda que o sentido subjetivo atua de forma processual e constante, não sendo, portanto, algo estático na formação da subjetividade.

Nessa perspectiva, visando atingir o objetivo proposto, buscamos interpretar as falas dos participantes/colaboradores da pesquisa, ou seja, os integrantes do Programa BALE, que atuam ou atuaram como mediadores de leitura, utilizando como principal estratégia a contação de história. Os colaboradores foram convidados a participar de forma voluntária da construção da investigação que compõe a tese de doutorado Expressão criativa e subjetividade na contação de histórias no Programa BALE (Biblioteca Ambulante e Literatura nas Escolas). Para este trabalho, precisamos salientar que enfocamos somente o aspecto relacionado à formação do leitor, com um recorte dos dados construídos a partir de um questionário aberto, no qual os contribuintes do estudo responderam a perguntas elaboradas a partir das principais categorias da pesquisa.

A partir das respostas presentes no questionário, podemos construir indicadores que levam a construção do conhecimento de acordo com a proposta teóricometodológica adotada, que pressupõe a construção de indicadores oriundos das informações fornecidas pelos participantes da pesquisa e da construção interpretativa realizada pelo pesquisador. De acordo com González Rey, propositor da epistemológica 
qualitativa, os indicadores se referem aos elementos que ao longo do processo de pesquisa, vão adquirindo significado através da ação do pesquisador. (GONZÁLEZ REY, 2005).

Nesse sentido, visando identificar os membros colaboradores da investigação foi utilizado o código BC (baleano/a Colaborador/a) acompanhado da numeração de 01 a 25, que corresponde ao total de participantes da pesquisa. O termo baleano é utilizado no dia a dia da convivência no espaço do programa como forma de identificar aqueles que atuam na equipe.

Para o objetivo do presente trabalho, evidenciamos a fala de alguns colaboradores sobre o significado da atuação no BALE para sua formação leitora, buscando perceber os movimentos na subjetividade apresentados a partir das interações realizadas no BALE. A título de exemplo, mostramos a fala da $\mathrm{BC} 02$ a respeito de sua relação com a leitura antes e depois da participação no BALE.

\begin{abstract}
$\mathrm{BC} 02$
Com o BALE aprendi que o acesso à leitura pode fazer a diferença na vida de alguns indivíduos (Crianças, jovens e/ou adultos) que encontram no mundo da leitura, não só informação, mas acima de tudo prazer, divertimento e realização pessoal. Antes do BALE eu realizava um trabalho com a leitura com meus alunos porque tinha a consciência que eles precisavam ler para crescer intelectualmente e que a leitura era boa para eles e até divertia-os. Hoje, compreendo, através das experiências vivenciadas, que ler é muito mais que isso. Ler é transformar-se, é contribuir para transformar o outrem, o contexto que vivemos, o mundo que nos rodeia. A leitura não é só importante porque traz conhecimento, a leitura é indispensável para vida de qualquer sujeito porque com ela, através dela vivemos/aprendemos a viver (QUESTIONÁRIO DA PESQUISA, 2017).
\end{abstract}

Percebemos na fala da BC 02, que a participação no programa BALE desencadeou uma nova significação para o trabalho com a leitura, bem como a respeito do lugar que a prática de ler ocupa na vida social hoje. O sentido subjetivo de ser leitor passou de necessidade intelectual e/ou divertimento para uma realização muito mais significativa, capaz de transformar a vida de quem a prática. Aqui, há indicadores de que a atuação da colaboradora no Programa BALE, modificou não só sua prática enquanto docente, mas também a forma de encarar a vida como um todo. Isso mostra que a subjetividade da BC 02, foi mobilizada pela ação enquanto baleana e alcançou um novo patamar.

A atuação da BC 02 dentro do programa BALE revela que essa movimentação operada em sua subjetividade a partir do contato com o público, proporcionou também um novo sentido subjetivo para o ato de ler, tanto no que se refere ao sentido da leitura em sua vida pessoal, quanto no tocante ao profissional, já que incorporou em seu fazer uma nova atitude com relação à leitura a partir da vivência no ambiente do BALE.

Sendo assim, inferimos que o novo sentido subjetivo atribuído à leitura advém da relevância social que a atuação do BALE representa. Como afirma González Rey, "[...] O sentido é produzido sempre dentro de práticas culturais, como a própria linguagem, mas é irredutível aos processos sociais e culturais que participam de sua gênese" (GONZÁLES REY, 2012, p. 25). O pensamento do autor reforça a relevância do trabalho desenvolvido no BALE ao apontar os processos sociais como práticas culturais que culminam na geração de novos sentidos a partir de uma produção simbólica que atua como mediadora no processo de formação cultural. 
Ainda de acordo com González Rey (2008), os processos simbólicos e de sentido que atuam na constituição da subjetividade e que são exclusivos do ser humano são construídos no decorrer das relações sociais do sujeito a partir do caráter simbólico que envolve os processos sociais. Estes, são responsáveis pelas modificações que se instalam no interior da realidade humana e que atuam na formação da personalidade e movimentam recursos subjetivos provenientes da ação do homem, assim como ocorre na subjetividade do BC 02 ao considerar-se com uma nova visão de leitura a partir do trabalho no BALE.

Nas falas da BC 08, BC 09 e BC 22, encontramos também indicadores da mobilização da subjetividade através da atuação no BALE. Ao se referirem ao significado que o trabalho no BALE apresenta para sua formação leitora, revelam o seguinte:

\section{$\mathrm{BC} 08$}

Antes de atuar no BALE a minha relação com a leitura não era muito agradável, eu não gostava de ler e só lia por obrigação, depois do BALE adquiri gosto pela leitura e hoje me considero uma verdadeira leitora. (QUESTIONÁRIO DA PESQUISA, 2017).

\section{BC 09}

Antes do BALE já lia, poucos livros, mas, lia. No entanto, não era uma leitura propriamente dita, pois não havia a construção do gosto pela leitura, este construí enquanto contava histórias. (QUESTIONÁRIO DA PESQUISA, 2017).

BC 22

O BALE me despertou para o mais belo da leitura, antes de participar do BALE tinha outra visão de leitura, uma leitura por obrigação, a partir do meu ingresso no Programa descobri várias maneiras de está trabalhando com a leitura e estimular o gosto e prazer em ler dos alunos e público ouvinte. Sem falar que eu não gostava muito de ler e isso trouxe algumas consequências e sofrimentos para minha formação, por exemplo quando eu ingressei na graduação tinha dificuldades na compreensão de alguns textos. Através de formações, atendimentos e atuação do Programa BALE despertei o prazer em ler e isso contribuiu para minha formação e autoformação. (QUESTIONÁRIO DA PESQUISA, 2017).

As participantes se referem ao BALE como o responsável pelo desenvolvimento do gosto pela leitura, ou seja, ao interagirem enquanto membros do programa construíram um novo sentido subjetivo para a prática de leitura, que foi o prazer que a literatura produz, que até então não haviam encontrado. É possível ainda perceber a emoção como sentido subjetivo presente na fala das participantes, este aparece de forma implícita, especialmente na voz da BC 08, que atribui ao BALE o fato de ter se tornado uma "verdadeira leitora."

Com base no posicionamento das participantes em relação ao BALE, percebemos uma mobilização de processos subjetivos advindos de fatores externos, como a interação possibilitada pelas atividades de contação de histórias, bem como de fatores internos, como a satisfação demonstrada nas falas. No tocante a esse aspecto, Scoz; Tacca e Castanho defendem que "[...] O interno e o externo integram-se em permanente influência mútua, o que permite sempre o surgimento de novos processos, numa relação dialética que integra o sujeito e suas relações sociais. [...]" (SCOZ; 
TACCA E CASTANHO, 2012, p. 137). Ao integrar-se nas relações sociais propiciadas pelo BALE, a movimentação subjetiva se dá integrando aspectos externos e internos, pois para as autoras citadas, a subjetividade não é linear, mas pluridimensional.

Corroborando com a perspectiva apresentada, Coelho aborda que "A subjetividade como um sistema de configurações organiza subjetivamente as experiências do sujeito [...]" (COELHO, 2014, p. 110), sendo essas experiências que vão mobilizar a subjetividade e trazer novos sentidos subjetivos que são mobilizados nas práticas sociais e no contexto cultural no qual o sujeito interage. Como vimos na fala da BC 22, que se refere ao BALE como responsável por sua autoformação, no programa é possível gerenciar a própria formação como um sentido subjetivo que mobiliza o sujeito e o faz perceber as suas necessidades formativas, bem como o alcance das mesmas a partir da dinâmica operacional desenvolvida nas atividades do BALE.

Ao atentarmos para a interpretação da fala da $\mathrm{BC} 09$, percebemos indicadores da atividade de contação de histórias como responsável por uma nova forma de vivenciar a leitura, pois a colaboradora alega que lia antes de participar do BALE, mas não encontrava prazer na leitura. No entanto, ao contar histórias no BALE, a BC 09 encontra na leitura uma forma de prazer que até então não conhecia, ou seja, a experiência enquanto mediadora, mobilizou um novo sentido subjetivo para a prática de ler, transformando também a subjetividade no que se refere à leitura.

Desse modo, consideramos o espaço do BALE como um ambiente mobilizador da subjetividade que favorece aos participantes o desenvolvimento de vários sentidos subjetivos, principalmente no que se refere à formação leitora, dado que, como vimos nas falas mostradas, ao se integrar nas atividades, os membros da equipe do programa modificam sua forma de concepção e prática da leitura.

\section{4 Últimas considerações}

Tentamos neste trabalho elaborar uma breve discussão em torno da temática da formação do leitor no Programa BALE e a mobilização de sua subjetividade, tendo como elemento de análise no processo de investigação um recorte dos dados elaborados para construção da nossa tese de doutorado.

Esses dados foram construídos a partir de um questionário respondido por membros do BALE. Retomamos aqui a ênfase em que se trata somente de uma amostra do questionário e que elegemos um aspecto específico para ser tratado no presente estudo. Este aspecto se refere à mobilização da subjetividade dos participantes no tocante a relação com a leitura.

Vimos ao longo das discussões, embasadas na teoria da subjetividade na vertente abordada por Gonzáles Rey (2005, 2007, 2012, 2015), que os colaboradores demonstram em suas falas a elaboração de alguns sentidos subjetivos advindos de sua atuação no BALE. Dentre esses sentidos subjetivos, vale destacar a mudança na relação com a leitura que passou a ser de prazer, bem como a construção de uma concepção de leitura como fonte auspiciosa de conhecimento e de transformação. Além disso, percebemos uma mudança na relação com leitura, tanto no nível pessoal, quanto no profissional.

Podemos enfim dizer que os participantes do Programa BALE constroem sua formação com base em uma subjetividade desenvolvida a partir da interação com o 
público e com os colegas no programa, o que vai ao encontro da natureza humana, enquanto ser social e dotado de cultura, encontrando no outro e na sociedade os subsídios para sua formação enquanto sujeito.

\section{Referências}

ANDRADE, A. M. Quem conta um conto aumenta um ponto: contadores de histórias no Distrito Federal (1991 a 2011). Brasília, 2012. 145f. Dissertação (Mestrado em história cultural) - Instituto de Ciências Humanas, Universidade de Brasília.

CALVINO, I. Por que ler os clássicos. 2. ed. São Paulo: Companhia das Letras, 2004.

CÂNDIDO, A. O direito à literatura. In: Vários escritos. 3. ed. São Paulo: Duas Cidades, 2004.

CAVALCANTI, J. Caminhos da literatura infantil e juvenil: dinâmicas e vivências na ação pedagógica. São Paulo: Paulus, 2002.

COELHO, C. M. M. A categoria de sentido subjetivo e os contextos educacionais: valor teórico e evidências empíricas. In.: MITJÁNS MARTíNEZ, A.; ÁLVAREZ, P. (Orgs.). O sujeito que aprende: diálogo entre a psicanálise e o enfoque históricocultural. Brasília: Liber Livro, 2014, p. 99-122.

COSSON, R. Letramento Literário: teoria e prática. 2. ed. São Paulo: Contexto, 2011.

GONZÁLEZ REY, F. L. A pesquisa e o tema da subjetividade em educação. Revista Psicologia da Educação. n. 13, $2^{\circ}$ sem, p. 09-15. São Paulo: 2001. Diponível em: https://revistas.pucsp.br/psicoeduca/article/view/32815/22634. Acesso: 09 de ago. de 2017.

Sujeito e subjetividade: uma aproximação histórico-cultural. São Paulo: Pioneira Thomson Learning, 2003.

. O valor heurístico da subjetividade na investigação psicológica. In.: GONZÁLEZ REY, Fernando Luiz. (Org.). Subjetividade, Complexidade e Pesquisa em Psicologia. São Paulo: Pioneira Thomson Learning, 2005a, p. 27-51.

- Pesquisa qualitativa em psicologia: caminhos e desafios. Trad. Marcel Aristides Ferrada Silva. São Paulo: Cengage Learning, 2005b.

Psicoterapia, subjetividade e pós-modernidade: uma aproximação históricocultural. São Paulo: Thomson Learning, 2007.

Subjetividad social, sujeto y representaciones sociales Revista Diversitas Perspectivas en Psicología, v. 4, n. 2, 2008, pp. 225-243, Universidad Santo Tomás Bogotá, Colombia.

Disponível

em: 
http://pepsic.bvsalud.org/scielo.php?script=sci_abstract\&pid=S1794-

99982008000200002. Acesso em 02.04.2018.

A configuração subjetiva dos processos psíquicos: avançando na compreensão da aprendizagem como produção subjetiva. In.: In.: MITJÁNS MARTÍNEZ, A.; SCOZ, B. J. L.; CASTANHO, M. I. S. (Orgs.). Ensino e aprendizagem: a subjetividade em foco. Brasília: Liber Livros, 2012, p. 21-41.

Pesquisa qualitativa e subjetividade: os processos de construção da informação. Tradução Marcel Aristides Ferrada Silva. São Paulo: Cengage Learning, 2015.

GONZÁlEZ REY, F. L.; MITJÁNS MARTÍNEZ, A. Subjetividade: teoria, epistemologia e método. Campinas-SP: Editora Alínea, 2017.

LARROSA J. Literatura, experiência e formação. In: COSTA, M. V. (Org.) Caminhos investigativos: novos olhares na pesquisa em educação. 2 ed. Rio de Janeiro: DP\&A, 2002, p. 133-160.

MITJÁNS MARTÍNEZ, A. Criatividade, personalidade e educação. 3. ed. Campinas/SP: Papirus, 1997.

A teoria da subjetividade de González Rey: uma expressão do paradigma da complexidade. In.: In.: GONZÁLEZ REY, Fernando. (org.). Subjetividade, complexidade e pesquisa em psicologia. São Paulo: Pioneira Thomson Learning, 2005, p. 01-25.

MONTENEGRO, M. E. O estudo da subjetividade na perspectiva histórico-cultural: um avanço nos clássicos. In.: MITJÁNS MARTÍNEZ, A.; SCOZ, B. J. L.; CASTANHO, M. I. S. (Orgs.). Ensino e aprendizagem: a subjetividade em foco. Brasília: Liber Livros, 2012, p. 43-57.

MUNIZ, D. M. S.; OLIVEIRA, J. A. de L. Mediadores sociais de leitura: pontes para experiência literária. PontodeAcesso, Salvador, v. 8, n. 2, p. 43-60, ago, 2014. Disponível em: www.pontodeacesso.ici.ufba.br. Acesso em 02.04.2018.

OLIVEIRA, M. K. Vygotsky: aprendizado e desenvolvimento, um processo sóciohistórico 4. ed. São Paulo: Scipione, 2002.

SAMPAIO, M. L. P. Eu faço extensão. InfoEXT. Pró-Reitoria de extensão da UERN. $\mathrm{n}^{\circ}$. 02. 2012. Disponível em: http://www.uern.br/controledepaginas/proex-noticiasinfoext/arquivos/1164infoext_2_edicao__proex_uern.pdf Acesso em 10/11/2016.

SAMPAIO, M. L. P.; MASCARENHAS, R. de O. Projeto Biblioteca Ambulante e Literatura nas Escolas (BALE): ação conjunta entre a universidade e a comunidade pauferrense. Projeto de extensão. Pau dos Ferros, 2007.

SCOZ, B. J. L.; TACCA, Maria C. V. R.; CASTANHO, M. I. S. Subjetividade, ensino e aprendizagem: contribuições de pesquisas acadêmicas. In.: MITJÁNS MARTÍNEZ, A.; 
SCOZ, B. J. L.; CASTANHO, M. I. S. (Orgs.). Ensino e aprendizagem: a subjetividade em foco. Brasília: Liber Livros, 2012, p. 131-155.

SISTO, C. Textos e pretextos sobre a arte de contar histórias. 2. ed. Curitiba:

Ed. Positivo, 2005.

VYGOTSKY, L. S. Pensamento e linguagem. Tradução Jefferson Luiz Camargo. 3. ed. São Paulo: Martins Fontes, 2005.

A formação social da mente: o desenvolvimento dos processos psicológicos superiores. Tradução José Cipolla Neto, Luís Silveira Menna Barreto, Solange Castro Afeche. 7. ed. São Paulo: Martins Fontes, 2007

Recebido em 17 de maio de 2019

Aceito em 03 de novembro de 2019 